\title{
Editorial
}

When we set about creating the journal a significant factor in favour of an online format was the ability to be responsive in a rapidly changing multi-disciplinary field. That way we could be particularly 'cutting edge' and perhaps even the first outlet to provide the space for a quality discussion and analysis on a given topical subject. This illustrates a somewhat clear relation between speed, production and competition. This is important in the field in which we research given the often heard criticism of commentary and regulation lagging behind science. However the confluence of speed, production and competition is also present in the very science we are interested in and recent events would urge caution against unreflected mimicry.

In Arthur Caplan and Glenn McGee's recent column (see http://blog.bioethics.net/) they argue that Science must slow its speed. In particular they make reference to the recent controversy over Korean cloning and stem cell scientist Hwang Woo Suk. Here it seems he raced ahead to try and gain a competitive advantage in the field of stem cell research cognisant of the prohibitive nature of the US regulatory environment. Unfortunately both ethics and science appear to have suffered. As Caplan and McGee put it: "They ran to get ahead of the world competition. Now it seems they ran so fast they fell down". The danger may be that stem sell research suffers generally. SCR is unlikely to have any immediate benefits and so a measured co-operative approach would surely be the best way to see if it can deliver upon its myriad of promises from radical solutions to human diseases to reductions in animal experimentation.

Similarly there is virtue in a slower reflective position in bioethics and social studies of science and technology. In being responsive to rapid developments we would do well not to fall into the same trap of quality being compromised by competitiveness or the simple reproduction of naïve scientism that uncritically becomes ensconced in overly optimistic discourses of breakthrough and progress. This we hope will guide us in our relevance to present and future issues so that we can exploit the speed of online delivery and production without running so fast we fall down. Measured topical submissions welcomed.

\section{Richard Twine}

Centre For Economic and Social Aspects of Genomics (CESAGen)

Lancaster University, UK 